LIMA, Maria Lúcia Costa. In: RODRIGUES, Adyr A. B. (ORG.), Ecoturismo no Brasil: possibilidades e limites, Editora Contexto, 2003, p.71-87.

\title{
(ECO)TURISMO EM UNIDADES DE CONSERVAÇÃO
}

\section{(ECO) TOURISM IN CONSERVATION UNITS}

Michele Souza da SILVA ${ }^{1}$

O referido capítulo consta na obra organizada por Adyr Rodrigues e traz uma contribuição a partir da análise realizada pela autora Maria Lúcia Costa Lima sobre as possibilidades do desenvolvimento de atividades ecoturísticas em Unidades de Conservação. Assim, a referida autora inicia o capítulo tecendo um breve perfil das modificações e do começo de uma maior consciência em prol do ambiente nas décadas de 60 e 70, e que de certa forma passou a influenciar no turismo, com atividades alternativas, que buscam impactar menos o ambiente e estabelecer uma conexão maior entre homem e natureza, que até então, neste período, ainda estava restrito a um público diferenciado voltado para aventuras, e após a década de 90 o turismo de natureza passa a se tornar atrativo para um maior público de pessoas que ainda não haviam se despertado para realização de viagens que saíssem dos tradicionais roteiros urbanos. Após a autora destaca o papel do crescimento de práticas relacionadas com o ecoturismo dentro das unidades de conservação pelo mundo e como esta vem se desenhando como uma possibilidade rentável e ao mesmo tempo conservacionista do ambiente em vários países, entretanto em outros países ela ainda é pouco explorada. Finalizando o capítulo a autora traz para a reflexão os impactos e as fragilidades que tais práticas podem trazer ao ambiente e as populações tradicionais, junto com as potencialidades que também poderão ser ampliadas tanto para o ambiente quanto para o social.

Conforme destaca a autora, a partir dos anos 70 e principalmente nos anos 90 temos um aumento das preocupações com as causas ambientais, e assim práticas voltadas para o ecoturismo passam a ser vistas como uma forma de reduzir atividades predatórias, que busca um público que escolhe estar presente em um ambiente preservado e pouco alterado, e assim esta pode promover a conservação bem como fortalecer a economia e beneficiar comunidades

\footnotetext{
${ }^{1}$ Doutoranda no Programa de Pós-Graduação em Geografia (PPGEO) da Universidade do Estado do Rio de Janeiro (UERJ). Mestra em Geografia pelo PPGEO (UERJ). Licenciada e Bacharela em Geografia pela Universidade Federal Rural do Rio de Janeiro (UFRRJ).

E-mail: michleal@hotmail.com
} 
rurais. As pessoas que procuram o turismo voltado para a natureza querem vivenciar o novo, o exótico, sair das rotinas de um ambiente urbano.

Desta forma, com a ampliação desse público que busca estar em contato mais próximo com a natureza, as unidades de conservação acabam tornando-se parte desse roteiro. Assim, a autora mostra alguns países como os Estados Unidos que utilizam os seus parques para receber visitantes e obtendo uma grande arrecadação em dinheiro a partir do desenvolvimento e recebimento de atividades turísticas nessas áreas protegidas.

A autora não traz somente como exemplo a exploração do turismo alternativo nos Estados Unidos, mas também em países considerados em subdesenvolvimento como a Costa Rica, o Quênia, que vem aumentando as suas receitas com abertura de suas áreas protegidas para práticas ecoturísticas.

No Brasil o desenvolvimento do ecoturismo em unidades de conservação ainda está sendo discutido, algumas unidades já realizam esta atividade, porém ainda são poucas, e o país possui uma grande potencialidade para ampliar o turismo voltado para a natureza, sendo realizado de forma organizada e coerente, tais práticas podem beneficiar a conservação ambiental, o desenvolvimento econômico e as populações locais que podem ampliar suas alternativas de renda e o sentimento de pertencimento, com a necessidade de preservação do ambiente em que vivem. A autora citando Lindberg e Huber (1995) destaca que em uma estimativa geral menos de $10 \%$ dos gastos do turista permanece nas comunidades próximas aos destinos ecoturísticos. É partir dessa citação que a autora faz, que podemos refletir sobre como as comunidades locais poderiam usufruir se participassem do ecoturismo, uma vez que essas possuem um grande conhecimento da área, e recebendo a capacitação correta para trabalhar com os turistas, poderia ocorrer um grande desenvolvimento econômico e social para as populações tradicionais, promovendo uma troca de saberes e experiências dessas populações com os visitantes.

Os benefícios do ecoturismo nas unidades de conservação são muitos, contudo a autora também destaca alguns custos e problemas que podem ser enfrentados, como toda atividade o planejamento é fundamental, além do correto manejo nas unidades para evitar que o ambiente seja impactado de forma negativa. Uma das principais limitações é o comportamento do visitante, que muitas das vezes não estão preparados para lidarem com um ambiente em sua forma natural, mais "selvagem" que portanto não oferece as benesses de um local mais urbanizado, assim a autora destaca Wearing e Neil (2001, p.75) relatando que para cada viajante que esta disposto a ir ao encontro a natureza como ela se apresenta, existem 
centenas de outros que solicitam um lugar modificado para o uso com rodovias pavimentadas, lanchonetes, instalações para piqueniques, banheiros e outras facilidades. Assim, para que de fato se possa promover o ecoturismo nessas áreas mantendo a sua conservação, é preciso antes de tudo formar um grupo de visitantes que as conhecem e estão dispostos conservá-las como estas são, sendo assim uma construção social voltada para a compreensão de preservação da natureza.

Como destaque em relação à visitação nas unidades de conservação a autora utiliza alguns autores com diferentes vertentes sobre a capacidade de um ambiente protegido para receber visitações. Da forma como o turismo é planejado e manejado ele pode ampliar o lixo e a deposição de resíduos, além do consumo de água e eletricidade. Kenchington (1989) fez um alerta em relação ao contínuo aumento de turistas no Parque Nacional de Galápagos. E a partir do debate sobre o aumento do número de turistas, é que se passou a destacar a necessidade de incluir nos estudos de manejo a capacidade de suporte ou de carga nos locais protegidos, de forma a mitigar os efeitos negativos sobre a fauna e flora. Porém, a autora utilizando Takahashi (1997) faz contraponto em relação a capacidade de carga, uma vez que para este autor o paradigma da capacidade de carga fracassou principalmente porque ele se preocupava demais com a questão do número, quando na verdade muitos dos problemas estão mais relacionados com o comportamento das pessoas e não em função da quantidade. Sendo necessárias intervenções educacionais para que o visitante possa respeitar e usufruir de forma consciente da natureza. Dessa forma, pode-se dizer que o tipo de uso, o comportamento dos visitantes, as condições biofísicas e de manejo e a época de uso são mais importantes no cálculo da capacidade de carga, do que simplesmente o número de visitantes.

No Brasil existem ainda diversas limitações, segundo um estudo realizado pela WWF (1999) sobre as áreas protegidas no país, foi constatado que 47 dos 88 parques e reservas pesquisados, essas áreas nunca foram implementadas de fato, apresentando problemas como: regularização fundiária, insuficiência de infraestrutura com pessoal especializado e equipamentos, ou seja, são unidades de conservação que apenas existem no papel, mas não estão sendo corretamente manejadas e geridas, muitas encontram-se em situação de abandono.

Assim, a autora conclui o capítulo ressaltando a importância de se ter uma avaliação critica na implementação do (eco)turismo nas unidades de conservação, não se pode ver esta forma como a única maneira de desenvolvimento e nem como conservação da natureza, da mesma forma a autora faz um destaque sobre o prefixo eco que não deve ser visto como palavra mágica que ira mitigar todos os "males" do turismo. E ainda que tenhamos diversos 
pontos positivos, a prática do ecoturismo ainda está longe de atingir o conjunto de seus propalados princípios e diretrizes. Mas ela não deixa de destacar que tal prática pode ser mais um dos instrumentos que podem apoiar na conservação, podendo também ser uma das alternativas socioeconômicas para diversas localidades que encontram-se a margem do desenvolvimento regional.

Partindo de minha análise com relação ao capitulo da referida a autora, este traz elementos muito importantes sobre o desenvolvimento de atividades de ecoturismo em unidades protegidas, uma vez que quando essas são corretamente geridas por profissionais capazes e especializados, podem ter um bom plano de manejo, permitindo a coexistência da visitação com a conservação ambiental. Neste planejamento considero importante a inserção das comunidades locais em todos os processos que deveria começar na própria criação da unidade de conservação. A população local tem muito a contribuir, e ao mesmo tempo, podem aproveitar das atividades turísticas para adquirirem uma fonte de renda. Quando inserimos todos os conjuntos da sociedade na conscientização pela manutenção do ambiente natural, temos maiores possibilidades de preservá-lo. Sendo assim, necessário estimular que o visitante, os moradores, profissionais e gestores conheçam a unidade de conservação em relação as suas potencialidades e fragilidades.

Considero este capítulo uma importante referência bibliográfica para os que pesquisam sobre o ecoturismo, e principalmente sobre as visitações em unidades de conservação. Uma discussão importante, sobretudo na atualidade, e que deve ser ampliada a partir de demais pesquisas.

Resenha recebida em 03-03-2019

Resenha aceita para publicação em 08-09-2020 